\title{
Practice Study of Mind Map in PBL Teaching of Ophthalmology for Five-Year Clinical Medical Undergraduates
}

\author{
Hao Chen ${ }^{1}$, Mingbao Gou ${ }^{1}$, Hui $\mathrm{Li}^{1}$, Xue $\mathrm{Wu}^{1}$, Yujia $\mathrm{Ji}^{1}$, Yanchun $\mathrm{Xu}^{1}$, Yiqing Niu ${ }^{1} \&$ Quanliang Zhao ${ }^{1}$ \\ ${ }^{1}$ Inner Mongolia Forestry General Hospital; The Second Clinical Medical College of Inner Mongolia University \\ for Nationalities, Hulunbeier, China \\ Correspondence: Quanliang Zhao, Inner Mongolia Forestry General Hospital; The Second Clinical Medical \\ College of Inner Mongolia University for Nationalities, Hulunbeier 022150, Inner Mongolia, China.
}

Received: January 15, 2022

doi:10.20849/aes.v7i1.1019

Accepted: February 16, 2022

URL: https://doi.org/10.20849/aes.v7i1.1019

Foundation item: The 13th Five-Year Plan of Education research in Inner Mongolia Autonomous Region.NO.NGJGH2020137.

\begin{abstract}
Objective: To explore the feasibility and effect of mind map in PBL teaching of ophthalmology for five-year clinical medical undergraduates. Methods: Forty five-year clinical undergraduates who studied in the Second Clinical Medical College of Inner Mongolia University for Nationalities from February 2021 to July 2021 were randomly divided into PBL combined with mind mapping group and PBL teaching group. Among them, 20 medical students applied the combination of mind mapping and PBL teaching method, and the other 20 medical students applied PBL teaching method to learn the theoretical knowledge and practical teaching of ophthalmology. The differences between the two groups were compared through questionnaire feedback, theoretical examination, practical examination and medical record writing. Results: The experimental group was better than the control group in theoretical scores and clinical skills, and there was no statistical difference in medical record writing scores. The experimental group and the control group were superior to the control group in self-learning ability, learning efficiency, memory and understanding ability. There was no statistical difference between the experimental group and the control group in clinical skills, clinical thinking, problem-solving ability, learning interest, team cooperation ability, and doctor-patient communication. Conclusion: the application of mind map in five-year undergraduate clinical medical ophthalmology PBL teaching can significantly improve the five-year undergraduate medical students' self-learning ability, learning efficiency, memory and understanding ability, which is worthy of promotion.
\end{abstract}

Keywords: medical education, mind map, PBL, ophthalmology

\section{Research Background}

In recent years, China's medical teaching has changed to PBL mode. In response to the national call, all colleges and universities have explored their own PBL teaching mode which is in line with their own conditions and have achieved some results (Wang, Luo \& Lu, 2021). Ophthalmology is a clinical subject that pays equal attention to theory and practice. Due to the precise and complex anatomical characteristics of the eye, the abstract eye movement characteristics and the difficult to understand refractive parameters (Zhou, Wei \& Ma, 2014), it is very difficult to change PBL ophthalmology teaching from "teaching-centered" to "learning-centered". In recent years, it has been found that the team members' ideas in reporting are not clear enough and they are unable to independently construct the knowledge system. Particularly, in the chapter teaching of strabismus and refractive error, the ability to achieve mastery through a comprehensive study is lacking, the practice and theory derail, and the learning efficiency is low. Glaucoma teaching students lack of logic level for the construction of knowledge, knowledge is limited to the content of this chapter, the lack of divergent thinking, clinical reasoning is not complete enough, practice links scripted, unable to contact multi-disciplinary theory, poor team cooperation ability. Mind map is an innovative teaching method, which can help students improve their divergent thinking ability, problem analysis ability and innovation ability (Wang, Chang \& Lei, 2021). For the above reasons, we applied mind map to PBL case discussion and summary learning to improve students' abilities of knowledge system construction and team collaboration, cultivate students' divergent thinking, and enhance medical students' 
clinical thinking ability.

\section{Objects and Methods}

\subsection{Subjects}

Forty five-year clinical undergraduates who studied in the Second Clinical Medical College of Inner Mongolia University for Nationalities from February 2021 to July 2021 were randomly divided into an experimental group (20 subjects) and a control group (20 subjects). The experimental group was treated with PBL combined with mind map teaching method, while the control group was treated with PBL teaching method to learn the theoretical knowledge and practical teaching of ophthalmology.

\subsection{Research Methods}

In the experimental group, Xmind software was used to guide students to construct mind map during PBL case discussion, while only routine PBL discussion was conducted in the control group.

Specific teaching programs of the experimental group: (1) Question design: The teacher asked questions in advance to discuss the symptoms, signs, pathogenesis, staging, diagnosis, differential diagnosis, treatment, and the latest research progress of ophthalmic diseases. At the same time, the mind map framework will be distributed. (2) Mapping of mind map in the experimental group: The teacher provided the clinical cases and the designed questions corresponding to the cases to the students before class. For the difficult problems, give appropriate tips for students to discuss the analysis of the reference, while explaining some of the corresponding concepts or provide the corresponding reference to help students in the analysis and discussion. The students divide group learning, consult textbooks and literature, carry out problem-centered thinking and discussion activities, and improve the mind map according to the requirements. They can also put forward new problems, expand the scope of learning and discussion, and enrich the mind map. (3) Group reporting, discussion and teacher's comment: In the class, one medical student was selected to show the mind map in the form of PPT to provide feedback on the learning content. The teacher was guided to learn the main points of symptoms, signs, pathogenesis, staging, diagnosis, differential diagnosis, treatment plan, and the latest research progress in each link. The advantages and disadvantages of each group in the discussion of PBL were commented, and the knowledge points were summarized and strengthened. The students were further required to improve the mind map after class.

The traditional PBL teaching method was adopted in the control group. (1) Question design: The teacher was asked questions in advance to discuss the history, precipitating factors, symptoms, signs, pathogenesis, staging, diagnosis, differential diagnosis, treatment regimen, and latest research progress of ophthalmic diseases. (2) The teacher should provide the students with the clinical cases and the designed questions corresponding to the cases before class. For the difficult problems, give appropriate tips for students to discuss the analysis of the reference, while explaining some of the corresponding concepts or provide the corresponding reference to help students in the analysis and discussion. (3) Group reporting: In the class, one medical student was selected to report the learning content and discussion results in the form of PPT. The main points of the teacher's knowledge in symptoms, signs, pathogenesis, staging, diagnosis, differential diagnosis, treatment, the latest research progress, etc.

Assessment methods: 1. Passed the examination, with the theoretical examination accounting for 60 points, practical ability for 20 points, and case analysis and writing for 20 points. 2 . The satisfaction survey, specific projects including self-learning ability, memory and understanding ability, problem-solving ability, learning efficiency, clinical thinking, clinical skills, learning interest, team cooperation ability, doctor-patient communication and overall satisfaction were recorded, 10 points per project.

\subsection{Statistical Methods}

SPSS 20.0 software was used for analysis and processing of the data. The measurement data were expressed as $(\overline{\mathrm{x}} \pm \mathrm{s})$ and $\mathrm{t}$-test, and $\mathrm{P}<0.05$ indicated that the difference had statistical significance.

\section{Result}

\subsection{Theoretical and Practical Ability Scores and Case Analysis Scores of the Experimental Group and the Control Group}

The theoretical score of the experimental group was 51.00 \pm 5.03 , while that of the control group was $45.75 \pm 6.54$ $(\mathrm{P}<0.05)$. The difference was statistically significant and the theoretical score of the experimental group was superior to that of the control group. The scores of practical ability in the experimental group and the control group were $16.90 \pm 1.74$ and $15.60 \pm 2.16$ respectively $(\mathrm{P}<0.05)$. The difference was statistically significant and the 
practical skill score in the experimental group was superior to that in the control group. The scores of medical record writing in the experimental group and the control group were $16.60 \pm 2.06$ and $16.30 \pm 2.05$ respectively $(\mathrm{P}>0.05)$. There was no significant difference. See Table 1 and Figure 1.

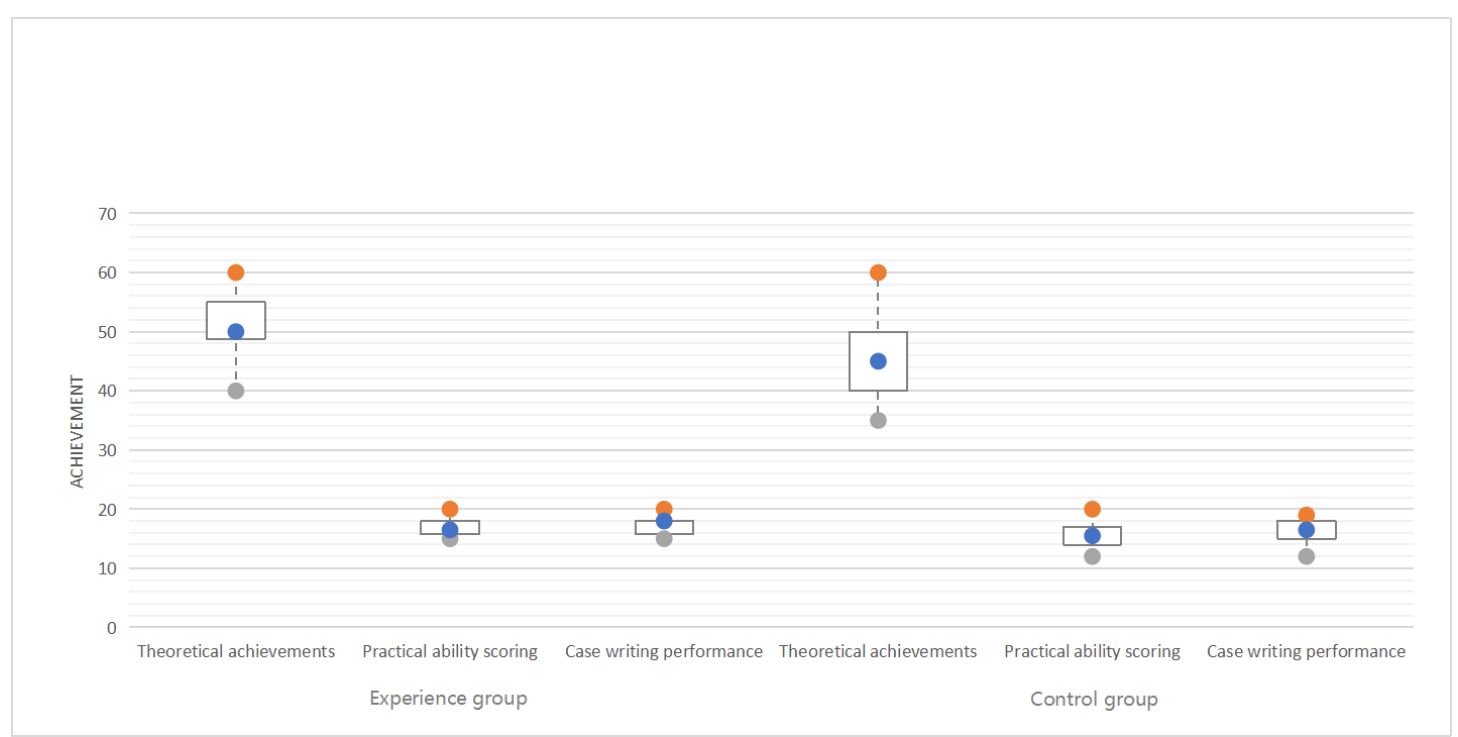

Figure 1. Theoretical and practical ability scores and case analysis scores of the experimental group and the control group

Table 1. Theoretical and practical ability scores and case analysis scores of the experimental group and the control group

\begin{tabular}{cccc}
\hline group & $\begin{array}{c}\text { Theoretical } \\
\text { achievements }\end{array}$ & Practical ability scoring & $\begin{array}{c}\text { Case writing } \\
\text { performance }\end{array}$ \\
\hline Experimental group & $51.00 \pm 5.03$ & $16.90 \pm 1.74$ & $16.60 \pm 2.06$ \\
Control group & $45.75 \pm 6.54$ & $15.60 \pm 2.16$ & $16.30 \pm 2.05$ \\
$\mathrm{t}$ & 2.85 & 2.09 & 0.46 \\
$\mathrm{P}$ & 0.00 & 0.02 & 0.32 \\
\hline
\end{tabular}

\subsection{Teaching Effect Questionnaire of Experimental Group and Control Group}

The scores of self-learning ability in the experimental group were $8.10 \pm 0.91$, while those in the control group were $7.40 \pm 0.94(\mathrm{P}<0.05)$. The difference was statistically significant and the self-learning ability in the experimental group was superior to that in the control group. The learning efficiency score of the experimental group was $8.50 \pm 0.69$, while that of the control group was $7.40 \pm 1.23(\mathrm{P}<0.05)$. The difference was statistically significant and the learning efficiency score of the experimental group was superior to that of the control group. The scores of memory and understanding ability in the experimental group were $8.75 \pm 0.44$, while those in the control group were $7.60 \pm 1.47, \mathrm{P}<0.05$. The difference was statistically significant and the scores of memory and understanding ability in the experimental group were better than those in the control group. The overall satisfaction score of the experimental group was $8.45 \pm 0.83$, while that of the control group was $7.80 \pm 1.11$ $(\mathrm{P}<0.05)$. The difference was statistically significant and the overall satisfaction score of the experimental group was superior to that of the control group. There was no statistical difference between the experimental group and the control group in clinical skills, clinical thinking, problem-solving ability, learning interest, team cooperation ability, and doctor-patient communication. 
Table 2. Teaching effect questionnaire scores of experimental group and control group

\begin{tabular}{lcccc}
\hline Questionnaire project & $\begin{array}{c}\text { Experimental group } \\
\text { score }(\mathrm{n}=20)\end{array}$ & $\begin{array}{c}\text { Control group } \\
\text { score }(\mathrm{n}=20)\end{array}$ & $\mathrm{t}$ & $\mathrm{P}$ \\
\hline Self - learning ability & $8.10 \pm 0.91$ & $7.40 \pm 0.94$ & 2.39 & 0.01 \\
Learning efficiency & $8.50 \pm 0.69$ & $7.40 \pm 1.23$ & 3.48 & 0.00 \\
Memory and understanding & $8.75 \pm 0.44$ & $7.60 \pm 1.47$ & 3.36 & 0.00 \\
ability & $7.90 \pm 0.55$ & $7.80 \pm 0.95$ & 0.41 & 0.34 \\
Clinical skills & $7.95 \pm 0.76$ & $7.90 \pm 0.85$ & 0.20 & 0.42 \\
Clinical thinking & $8.65 \pm 1.04$ & $8.15 \pm 1.04$ & 1.52 & 0.07 \\
Problem solving ability & $7.50 \pm 1.24$ & $7.65 \pm 1.18$ & -0.39 & 0.35 \\
Learning interest & $8.25 \pm 0.91$ & $8.15 \pm 0.93$ & 0.34 & 0.37 \\
Team cooperation ability & $6.95 \pm 1.10$ & $7.05 \pm 1.15$ & -0.28 & 0.39 \\
Doctor-patient & $8.45 \pm 0.83$ & $7.80 \pm 1.11$ & 2.11 & 0.02 \\
communication & & &
\end{tabular}

\section{Discussion}

Ophthalmology is a clinical discipline that pays equal attention to theory and practice. Due to the precise and complex anatomical characteristics of the eye, abstract eye movement characteristics and difficult to understand refractive parameters, and the need for comprehensive analysis of ocular complications of various diseases, such as diabetic retinopathy, hypertensive retinopathy and retinal vascular disease, comprehensive and detailed diagnosis, differential diagnosis and treatment are carried out, and multi-disciplinary knowledge is involved in the process. PBL case teaching method can cultivate medical students' autonomous learning, thinking ability, problem analysis and problem solving ability, and improve students' clinical critical thinking ability and team cooperation ability (Lin, 2002). However, it is found in the process of ophthalmology teaching that students lack the ability to construct systematic knowledge system and clinical thinking framework, which leads to low learning efficiency and disorderly opinions on problems, resulting in prolonged teaching time. Some students reflect the need to spend a lot of time to construct knowledge system independently. The students with poor memory and understanding abilities are not conducive to team cooperation, resulting in the overall efficiency decline. For this reason, many innovative teaching methods have been introduced in colleges and universities to improve this deficiency, such as three-dimensional questioning method (Liu, Dong \& Xiao, 2020; Ou, 2016), scene simulation method (Zhang \& Zhou, 2021), reverse classroom teaching method (Shang, \& Jiang, 2016) and so on. The Teaching and Research Group of Ophthalmology in the Second Clinical Medical College of Inner Mongolia University for Nationalities and its own advantages have introduced mind map combined with PBL case teaching into the classroom and obtained good feedback.

Mind map is a thinking training tool. With the help of the mentor's mind map framework, the branches in the mind map drawing process can be expanded indefinitely, which is an effective tool to represent divergent thinking (Buzan, 1993). The help of mind map helps to associate new knowledge with old knowledge and to establish a systematic, networked and organized knowledge system, in which students' logical thinking ability can be cultivated. It can be improved many times before, in and after class to improve students' learning efficiency, autonomous learning ability, and memory and understanding ability.

Mind map can effectively improve learning efficiency (Yu, Wang, Jia, Gao, \& Zhao, 2017). In this study, the experimental group and the control group in the learning efficiency score, the experimental group was significantly better than the control group. In the simple PBL teaching mode, the main line of student discussion is not clear enough, the organization is not rational enough, and the logic level is chaotic. However, the teacher organically linked the general subject headings with the help of the mind map through the organization structure diagram, which can clearly show the correlation between complex clinical problems and basic knowledge points. Through self-study, the students consulted the literature pertinently with the help of the mind conductor framework, and further supplemented the mind map, thus greatly improving the learning efficiency.

Mind map can improve students' memory and understanding ability (YiSha, Duan, Zuo, \& et al., 2016; Song, 
Ding, Qi, \& et al., 2014). In this study, the experimental group and the control group in the memory and understanding ability score, the experimental group is significantly better than the control group. Through the group discussion and PPT report in class, the teacher can solve the difficult problems, which can constantly stimulate the thinking of the learners and carry out in-depth and broader exploration for specific problem situations. This can better promote the development of students' divergent thinking, for medical students can better exercise the thinking ability of clinical assumptions and clinical reasoning, and strengthen the students' understanding ability (Wang, Chang, \& Lei). Students improve their memory and understanding ability by improving the mind map before, during and after class.

To sum up, mind map is applied in PBL teaching of ophthalmology for five-year medical undergraduates, and it can significantly improve their self-learning ability, learning efficiency, memory and understanding ability, which is worthy of application.

\section{References}

Buzan, T. (1993). The mind map book: Radiant thinking-the major evolution in human thought.

Lin, L. (2002). Basic points of application of PBL teaching method in clinical medicine teaching. Journal of Shanxi Medical University (Basic Medical Education Edition), 4(4), 265-267.

Liu, H.-R., Dong, J., \& Xiao, H.-Q. (2020). Effects of mind map and three-dimensional questioning approach on innovative thinking ability of medical students --- A case study of otorhinolaryngology head and neck surgery teaching. Higher Medical Education in China, (8), 111-112.

Ou, Z. (2016). The effect of case-guided stereoscopic teaching method in cardiovascular disease internship for medical students. China Continuing Medical Education, 8(12), 10-11.

Shang, Y., \& Jiang, D. (2016). Exploration of application of turnover classroom in medical immunology teaching. Chinese Journal of Immunology, 32(8), 1222-1224.

Song, W., Ding, J., Qi, X, et al.. (2014). Application of Mind Map in Teaching and Learning of Medical Immunology. Springer Netherlands.

Wang, Q.-X., Chang, W.-X., \& Lei, T. (2021). Application of hierarchical progressive mind map in clinical thinking ability training of general residents. Chinese Medical Education after Graduation, 5(3), 273-277.

Wang, Q.-X., Chang, W.-X., \& Lei, T. Application of hierarchical progressive mind map in clinical thinking ability training of general residents. Chinese Medical Education after Graduation, 5(3), 5.

Wang, Y.-Y., Luo, X., \& Lu, H.-X. (2021). The practice of assessment in PBL case teaching of basic medicine. Basic Medical Education, 23(10), 707-710.

YiSha, L.-I., Duan, L.-P., Zuo, X.-X., et al.. (2016). Application of Mind Map and Standardized Patient in Internal Medicine Probation Teaching. Medicine Teaching in University (Electronic Edition).

Yu, W.-J., Wang, Q., Jia, G.-T., Gao, Z.-Q., \& Zhao, C.-L. (2017). Application of Mindmap in the Teaching of Cell Biology of Medical Students. International Conference on Modern Education and Information Technology (MEIT 2017). https://doi.org/10.12783/dtssehs/meit2017/12824

Zhang, Q.-D., \& Zhou, H.-L. (2021). Practical effect of scene simulation teaching method combined with mind map in nursing teaching rounds of diabetic ketoacidosis. Health and Vocational Education, 39(18), 112-114.

Zhou, X.-Q., Wei, S., \& Ma, X.-Y. (2014). Reflections on the reform of eight-year ophthalmology education. Northwest Medical Education, 22(4), 812-815.

\section{Copyrights}

Copyright for this article is retained by the author(s), with first publication rights granted to the journal.

This is an open-access article distributed under the terms and conditions of the Creative Commons Attribution license (http://creativecommons.org/licenses/by/4.0/). 